\title{
Research on the Problems and Routing Optimizations of Chinese Enterprise Marketing
}

\begin{abstract}
:
With the development of Chinese socialist market economy, enterprises have also continued to improve their own marketing tools, which lead to the marketing in China from scratch to continuous development. But we cannot ignore the problems of current enterprise marketing, if these problems can not be solved, it will restrict further development of economy. Now let us combine the knowledge we learned and related data to analysis the problems and put forward the corresponding methods.
\end{abstract}

Min Zhang ${ }^{1}$ Yinghua Gong ${ }^{1}$ and Jiyong Du ${ }^{1}$

${ }^{1}$ Handan Polytechnic College, Handan, China

Keywords: Marketing; Problems; Routing Optimizations

\section{Introduction}

Company is an organization for profit and its profits come from product sales and provided services, but the process to implement mostly depended on marketing operation. Market is becoming more and more competitive in the current market conditions, enterprises who want to win the competition must be accessed through dedicated network sales and business marketers' marketing tool, so that they can get consumers' recognition and acceptance by their products and services. But in practice, the majority of enterprises still adhere to the ideas of traditional production, products and marketing. There are some problems of inventory products, increasing receivable accounts and cash flows because of the blindly promoting products. Enterprise can not meet the requirement of a market economy owing to market's insufficient development ability, low product innovation and awareness of brand.

\section{Problems of enterprise marketing in China}

\subsection{Traditional concept and insufficient knowledge of marketing}

With the further development of China's socialist market economy, domestic market is becoming into a buyer's market from a seller's market, strengthen the marketing has become the focus of enterprise management. But some of them still pursue the traditional concept, namely "manufacturing-according-to-sales". Enterprises who regard the products as the center and ignore the customers' demand will lead to a large products backlog and cash-flow difficulties. In addition, a single marketing and backward in formulating marketing policies has been caused by not fully analysis and use consumers' shopping psychology. There are some enterprise decision-makers lacking of enterprising spirit not bold but hesitant in the fierce market competition, and afraid to take risks. When marketing is in trouble, they can not timely put forward emergency improvement mechanism, but negatively wait for the improvement of external conditions, that will cause the missing opportunities or the enterprise bankruptcy.

2.2. Lacking of management roles and duties in senior marketing and uncoordinated functions of marketing in departments

The absence of senior marketing management causes departments except marketing department can't adequately perform its functions, and departments cannot form a positive communication across the enterprise causing the light business 
management situation. At present, most senior executives in companies are paying much more attention to marketing work. But the "value" has a significant locality, uncertainty and non-process which results in a shortage of senior management. It also brings many hazards: first is failing to make full use of its marketing advantages in other departments, and its overall marketing function has been greatly weakened. And then is the slowly decision-making causing the problems of efficient sales work not timely and effectively solved. While it makes negative impacts on enterprise marketing performance, at the same time it fall business staff work enthusiasm. Last but not the least is the absence of top management which causes the lack of marketing direction.

\subsection{Poor abilities of market development in enterprise and marketing space}

With the emergence of a buyer's market, consumer's attitudes and buying behaviors have undergone profound changes in their requirements on variety, quality and color of the products, and they choose their own suitable products by constant comparison. Competitions among enterprises have also entered a white-hot stage. Facing with the marketing war, many companies are contented with the present consumer market but to develop new markets, the result can only be an out of the only market eventually. Therefore enterprises must put the needs of customer in the first place, increase their marketing ability, constantly do scientific subdivision of the market, and then use the appropriate marketing strategy to go into target markets.

\subsection{Shortage of new product development and weak awareness of brand in enterprise}

Development of new products is a guarantee of the initiate in market and a root of sustainable development in enterprise. With the promoting of science and technology, producing new generations of products is at an accelerated speed. Some companies are gradually eliminated by the market because of not paying attention to the development of new products but to self-fulfilling, which cannot adapt to consumers' needs of individual. Consumers' attitudes are also changing themselves with the development of modern economic life. Popular products can't keep up with consumers' fashion though are well-made in the past or in the present. While a large number of enterprises are fuzzy about brand strategy and lack of awareness and approach of it, which cannot make the enterprise bigger and stronger. Visibly, companies in order to maintain their competitive edge must continually develop new products with market demand and build up brand awareness.

\subsection{The neglect of functions about marketing network}

Now in the competitive market competition, most enterprises are not making full time in marketing network. There is no plan and no goal to sell their products but only to pay attention to product production. It is not only a waste of marketing resources, but also a bad marketing performance. Also there are many problems in the market position, promotions and others of current enterprise. In addition, marketing work has no point and no direction because of ignoring the correct market orientation and not targeting the market with respective regional characteristics. And shortage of marketing talent restricts the enterprise marketing ability enhancement in a certain extent.

\section{Routing optimizations to solve the problems.}

\subsection{To set up scientific marketing ideas adapted to market economy}

Market was regarded as a starting point of the production process in modem marketing. Enterprises must understand, analyze market demand, regarded market demand as a start of production before companies making decisions on the production. This is a new kind of business ideas of viewing consumers as the center, buyer's 
needs as the center and customer needs as the Centre. The basic features are guiding consumption and development needs. The precursor business marketing is the concept of innovation. Chinese enterprises should not only establish the marketing idea, but also set up a new marketing concept adapted to the market economy. From the perspective of the enterprises in China, we should establish the following concepts at least: first is knowledge marketing concept, second is global marketing concept and last is green marketing concept.

\subsection{To enhance the quality of marketing personnel and establish a professional marketing team}

At present the weakest link of China's enterprise marketing is poor quality of marketing personnel and the lack of a professional marketing team, which directly leads to the out of control and financial risk in company's own marketing system and customer system. Professional marketing personnel should possess higher quality and professional knowledge, be loyal to their duties, strictly comply with company rules, regulations and also have a very strong sense of initiative and entrepreneurship. Marketing team composed of professional staff will control the sales channel a good performance based on the internal management. Currently, the most important work need to be done is a solid construction for human resource and a basic management, rather than an excessive speculation and packaging.

Excellent marketing staff should have good abilities of psychological and adjustment to the setbacks at marketing work. Marketers need to master relevant product technical knowledge. Some high-tech enterprise product sales require specialized knowledge after the recruitment marketing staff training, related professional knowledge learning. Enterprise should do a reasonable selection and training based on the relevant standards, improve the comprehensive quality of marketing personnel and build the professional marketing team.

\subsection{To improve the development ability of enterprise in market and strengthen the competitiveness of marketing}

Market development is an important part of enterprise development, so enterprises should reasonably develop the market under the correct guidance of marketing idea. In order to develop market, we should firstly accord to the enterprise's social environment, industry environment, competitor status, their status and customer systems integration analysis, then do scientific market segmentations, and target markets with optimal marketing strategies.

\subsection{To enhance the ability of developing new products and maintain competitiveness}

"Ever products new, ever green enterprises", it is a popular saying in the business community. It tells us that only through constant product innovation, enterprises can maintain full of vitality. Old products and backward enterprises have been in a difficult position in the increasing fierce market competition. We must rely on the constantly developing marketable new products in order to occupy a dominant position in market competition. The key to build a competitive advantage is a deeper extent to meet consumers' needs than our competitors. Thus companies need to continue a new increase in the value of the product features and benefits, to win the sensitive consumers' attention and interest by different features of products and gain a competitive advantage.

\subsection{To accelerate the strategy of brand and establish a corporate brand}

In the modern economy, brand is a kind of strategic assets and an important source of core competitiveness of enterprises. From a perspective, competitiveness of enterprise is the brand competition. The one who can properly apply the brand strategy will win the market. Thus enterprises must make efforts for the implementation 
of brand strategy to better meet consumer needs. The first is a strict quality management based on international standards, which from decision-making, design, manufacture, testing, sales to after-sales service carries on a comprehensive, rigorous quality control, to ensure that the product is of high quality and efficiency. The second is the development of marketable products on the international market, particularly goods to meet consumer preferences. Brand is also "people", a credible and a certain well-known product brand name to the public. Only to develop products suited for consumer demand can increase their market share. The third is to strengthen management, make a brand name as a leader to set up modern enterprise groups. Basing on the existing enterprises of brand products manufacturing and with a link of assets, cross-border cross-industry cross-ownership enterprises of less competitive to merger, hold, acquire and establish modern enterprise group, then expand the scale of assets and management of brand-name enterprises industries of scale, improve enterprise asset efficiency and international competitiveness.

\subsection{To develop a suitable marketing network and strengthen the practical ability of marketing}

The circulation of commodities is promoted by marketing network. With the further development of market economy, the awareness of the enterprise marketing increases and the network has also been given the important function of marketing. Enterprises should change the traditional concept of network only for the sales channel, recognize the significance of present network of enterprises, and set up their own marketing network. First of all, companies should do a segmentation aimed at the demands of consumers in the market, which based on geography, population and so on. Then do specific segmentation according to market characteristics and marketing resources. Finally, enterprises should mobilize their own marketing resources, assign to the market, and strengthen the links between market segments, formation and efficient network. Even can build their own marketing networks and carry out large-scale constructions, to ensure that companies remain invincible in the competition.

\section{Conclusion}

With the development of Chinese socialist market economy and deep reform and opening up to the world, the environment faced by enterprises will be more complex, thus its market strategies should constantly adjust it. Enterprises should establish a correct view of marketing, use reasonable means of market development, accelerate the speed of development of new products, establish consciousness of brand strategy, build efficient and scientific marketing networks in order to adapt changing market demands and satisfy customers' needs, so that enterprises become gradually stronger in the competition.

\section{References}

[1] Yang Weidong, "The Enterprise Marketing Innovation Thinking," Modern Economic Information, 37-38, 2011.

[2] Yang Baozhen, "Strategy Innovation of Enterprise Marketing," Enterprise Economy, 76-78, 2011.

[3] Liu Zhi, "China's Small and Medium-sized Enterprise Marketing Problem Analysis," Modern Marketing (school edition), 42-43, 2012.

[4] Sun Liying, "Small and Medium-sized Enterprise Marketing Problems and Countermeasures," Journal of Shandong Social Science, 182-185, 2013.

[5] Yang jie, "China's Small and Medium-sized Enterprise Marketing Problem Analysis," Journal of Management, The Preceding 292, 2013. 